\title{
The effect of turbidity and prey fish density on consumption rates of piscivorous Eurasian perch Perca fluviatilis
}

\author{
Lene JACOBSEN, ${ }^{1 *}$ Søren BERG, ${ }^{1}$ Henrik BAKTOFT, ${ }^{1}$ P. Anders NILSSON,${ }^{2}$ Christian SKOV ${ }^{1}$ \\ ${ }^{1}$ National Institute of Aquatic Resources (DTU-Aqua), Technical University of Denmark, Vejlsøvej 39, 8600 Silkeborg, Denmark; \\ ${ }^{2}$ Department of Biology, Lund University, Sölvegatan 37, Lund, 22362 Sweden \\ *Corresponding author: 1j@aqua.dtu.dk
}

\begin{abstract}
Predator-prey interaction strengths in variable environments constitute a fundamental link to the understanding of aquatic ecosystem responses to environmental change. The present study investigates the effects of visibility conditions and prey fish density on predation rates of visually oriented piscivorous Eurasian perch Perca fluviatilis $L$. This was done in outdoor mesocosm $\left(16 \mathrm{~m}^{2}\right)$ experiments with clear water and two levels of turbidity (25 and 105 NTU) and two prey fish densities [3.1 and 12.5 roach Rutilus rutilus (L.) individuals $\left.m^{-2}\right]$. Perch consumption rates were affected by visibility less than expected, while they were highly affected by increased prey fish density. Perch responded to high prey density in all visibility conditions, indicating that prey density is more crucial for consumption than visibility in turbid lakes.
\end{abstract}

Key words: visibility, roach prey, mesocosm, piscivory, hunting mode.

Received: July 2013. Accepted: September 2013.

\section{INTRODUCTION}

Predation is a fundamentally important structuring force in aquatic ecosystems, and the understanding of how changing environmental conditions affect predator-prey interactions plays a key role in the comprehension and prediction of system responses to environmental changes. Many fish predators and their prey rely on vision for their success (Guthrie and Muntz, 1993), and the efficiency of vision depends on an unobstructed space between viewer and object. Poor visibility could be viewed as obstructive or advantageous for predators and/or prey, depending on their behaviour. For instance, degraded visibility could increase prey chance of avoiding predation, while it may decrease predator foraging efficiency (De Robertis et al., 2003). The consequences of visibility conditions for predator-prey interactions depend on effects on detection, attack and escape abilities (Ranåker et al., 2012).

Encounter rates depend on visibility conditions (Miner and Stein, 1996; Skov et al., 2007), prey density, as well as prey and predator behaviour (Nilsson, 2001). Antipredator behaviour in prey can be abandoned in low visibility conditions (Abrahams and Kattenfeld, 1997) with consequences for prey distribution and encounters. At the same time, reduced visibility decreases detection distance for both predators and prey, making predictions of predator-prey encounters in poor visibility complicated (Turesson and Brönmark, 2007; Wellington et al., 2010; Ranåker et al., 2012).

Eurasian perch Perca fluviatilis L. 1758 is common in North European, temperate, clear-water lakes, and uses vision as a main mode for detecting prey (Diehl, 1988; Craig,
2000; Jeppesen et al., 2000). Being actively cruising predators (Eklöv, 1992; Turesson and Brönmark, 2004), large piscivorous perch may suffer reduced foraging efficiency from decreased visual opportunity to detect prey (Craig, 2000). Laboratory experiments have demonstrated a negative effect of chlorophyll (Chl) turbidity on fish larvae consumption by juvenile $(12-14 \mathrm{~cm})$ perch (Radke and Gaupisch, 2005; Pekcan-Hekim and Lappalainen, 2006), but no effect of clay turbidity (Radke and Gaupisch, 2005), as is in studies of related species [i.e. yellow perch Perca flavescens Mitchell, 1814 (Abrahams and Kattenfeld, 1997); largemouth bass Micropterus salmoides Lacepède, 1802 (Reid et al., 1999)]. Studies of juvenile perch foraging on invertebrate prey have shown foraging rates to be affected by turbidity to a variable degree (Granquist and Mattila, 2004; Nurminen et al., 2010; Wellington et al., 2010). Knowledge on the ability of large piscivorous perch $(>200$ $\mathrm{mm}$ ) to consume fish prey in turbid waters is however limited to a recent telemetry field study that could not control for local prey densities (L. Jacobsen, unpublished results).

The present study investigates the effects of turbidity and prey density on consumption rates of large perch in outdoor mesocosm pools with artificial vegetation, intending to allow for natural behaviour of fish. The study design aims to disentangle the effects of visibility conditions and prey density that commonly co-vary in natural systems, on large perch piscivory, to explain perch persistence in highly turbid and productive lakes. It is hypothesised that i) perch have a lower consumption rate at high turbidity compared to clear water, and ii) increased prey fish density increases consumption rates regardless of turbidity. 


\section{METHODS}

\section{Experimental arena}

The experiment took place from 23 August to 6 October 2006 and was carried out in four outdoor mesocosm pools $(4 \times 4 \mathrm{~m}, 0.8 \mathrm{~m}$, water level $=0.4 \mathrm{~m})$. The pools were protected from birds by thin white plastic coverings and net walls. The coverings protected the pools from direct sunlight, but allowed ambient light levels. Each pool was divided into a macrophyte section $\left(5.2 \mathrm{~m}^{2}\right)$, made by artificial ivy mounted in high density on a steel frame, and an open water section $\left(10.8 \mathrm{~m}^{2}\right)$, acknowledging the importance of structural complexity in a natural environment (Diehl, 1988). The size of the pools and the presence of macrophytes facilitated near natural behaviour of the prey fish, with possibility of hiding and escaping, thus minimising experimental stress. Further, each pool was mounted with a net bag that was lifted at the end of each trial to collect fish.

Experiments were carried out under three visibility conditions: clear water, moderate turbidity [25 \pm 4.7 mean \pm standard deviation (SD) nephelometric turbidity units (NTU); Secchi depth: $32 \mathrm{~cm}$ ], and high turbidity (105 \pm 13 NTU; Secchi depth: $13 \mathrm{~cm})$. The visibility conditions evaluated in this work do occur in lakes in temperate Europe, although the extremes of perfectly clear and high turbidity may occur only locally or occasionally [e.g. Berg (1998) and Jeppesen et al. (1999) report Secchi depths ranging 14-610 $\mathrm{cm}$ in the region]. All fish originated from intermediately turbid environments (Secchi depths of $67-128 \mathrm{~cm}$ ), and were thus not adapted to either clear or high-turbidity water.

Turbid water was created by adding concentrated solutions of kaolin clay. Pilot experiments showed that a bulk proportion of the kaolin clay settled during the first hours after addition, and kaolin was therefore allowed to settle for $6 \mathrm{~h}$ before fish was stocked in the pools and the experimental period started. Pools were also equipped with circulation pumps in order to minimise settling during trials. Turbidity was monitored by use of a turbidity meter (Turbidimeter AL450T-IR; TurbiDirect, Dortmund, Germany) in each pool at the beginning and the end of each trial. At the same times, oxygen levels were monitored to ensure that they were adequate ( $>92 \%$ saturation), and temperature was logged every 15 min by Tidbit ${ }^{\circledR}$ loggers (Onset Computer Corp., Bourne, MA, USA).

\section{Experimental protocol}

Two prey fish densities were tested: low [50 roach $R u$ tilus rutilus (L. 1758) per mesocosm $=3.1$ roach $\mathrm{m}^{-2}$ ] and high $\left(200\right.$ roach per mesocosm $=12.5$ roach $\left.\mathrm{m}^{-2}\right)$.

Perch and roach for experiments were caught by seine netting in nearby lakes. Before experimentation, perch were acclimatised to holding conditions for 10-20 days. During holding they were fed daily with prey fish (roach) but were starved for $72 \mathrm{~h}$ before taking part in experiments. Prey fish were kept in tanks for 3-10 days before use being fed on aquarium feed flakes. Each fish participated only once in experiments.

Experiments were run with three piscivorous perch in each trial, based on perch behavioural trait as group foragers. Each trial was run for $16 \mathrm{~h}$, starting $8 \mathrm{~h}$ before sunrise and ending $8 \mathrm{~h}$ after sunrise (exact time adjusted to daylight changes). This way all trials were subjected to the same light regime and experimental fish were allowed to acclimatise to pool condition during the dark period. Prey [mean total length (TL): $50 \pm 5 \mathrm{SD} \mathrm{mm}$ ] and predators (mean TL: $249 \pm 30$ SD mm) were stocked in the pools at the start of each trial. At the end of the trial, experimental fish were collected and measured. Total length of a random sample of prey fish was measured, and surviving roach were later released into their lakes of origin. All perch were measured (TL), euthanised by a lethal dose of benzocaine, and the stomach content preserved for later analysis of ingested prey. There was no significant difference between TL of perch used in the different treatments (Kruskal-Wallis test, $\mathrm{P}=0.319$ ).

To avoid effects of time (water temperature changes) on results, treatment order was semi-randomised over time by distributing all treatments to be run twice every second week. Mean temperature during experimental period was $15.4 \pm 1.1 \mathrm{SD}^{\circ} \mathrm{C}$ (range: $13.4-17.1^{\circ} \mathrm{C}$ ) and there was no difference among temperatures across turbidity treatments [analysis of variance (ANOVA), d.f. $=2, \mathrm{~F}=0.185, \mathrm{P}=0.83$ ] or across prey densities (ANOVA, d.f. $=1, \mathrm{~F}=0.53, \mathrm{P}=0.59$ ). Treatment combinations were also randomly distributed among the four pools and the location of the macrophytes in each pool was randomly assigned for each trial. All combinations of turbidity level and prey density were repeated eight times, to reach a total of 48 experimental trials.

\section{Data treatment}

Per capita consumption rates were estimated as the mean number of prey fish in the three perch stomachs from each pool examined after trial termination. It was possible to estimate the number of roach ingested from the stomach contents since gut evacuation rate is more than $20 \mathrm{~h}$ for perch at the water temperatures established (Persson, 1979; Craig, 2000).

The effect of turbidity and prey density on perch consumption rate was analysed using a generalised least square model with turbidity and prey density included as fixed factors, along with their interaction term. Due to violation of model assumptions (variance homogeneity), a variance structure allowing for differing variance per turbidity and prey density strata was included. Statistical analyses were conducted using R v2.15.0 (R Development Core Team, 2012) and the nlme-package v3.1-103 (Pinheiro et al., 2012) following Zuur et al. (2009).

\section{RESULTS}

All experimental fish looked healthy during trials and no unintended mortality occurred. On average, perch took 
2.1 \pm 1.4 SD prey fish per capita in high prey density and $0.4 \pm 0.5 \mathrm{SD}$ prey fish per capita in low-density treatments. Some individual perch did not eat, but this was mainly in trials with low prey density and turbid conditions. The two-way interaction term between prey density and turbidity was not significant $(\mathrm{P}=0.70)$ and therefore eliminated in the final model. The generalised least square model showed that the effect of turbidity on consumption rates was almost significant (Tab. 1, Fig. 1), suggesting reduced consumption in high turbidity. The effect of prey density was highly significant (Tab. 1), showing a proportional increase of prey consumption rate relative to prey density regardless of turbidity (Fig. 1).

\section{DISCUSSION}

Perch consumption was not as clearly affected by high turbidity as hypothesised; it seemed that perch were capable of hunting for prey fish even in very high turbidity and at low prey densities. Moreover, consumption rates in turbid water were higher at high prey density. Since prey density is commonly higher in eutrophic turbid lakes than in clearwater lakes (Jeppesen et al., 2000), this study supports the idea that increased prey density can compensate for the visual foraging constraints in turbid waters. It is acknowledged that Turresson and Brönmark (2007), unlike the present study, did not find that high prey density in turbid waters could compensate for the reduced reaction distance in visually hunting sit-and-wait pike (Esox lucius L. 1758), measuring encounters and not consumption.

In the present experimental design, turbid water did not allow for collection of behavioural data on predators or prey. Hence, it can only be speculated if behavioural compensatory mechanisms, e.g. changes in activity, influence how large perch manage to maintain consumption rates in turbid water. A recent field study has indicated that perch in a turbid lake change diel activity pattern to include night activity (L. Jacobsen, unpublished results), so that allocating extended time to foraging can facilitate feeding in low-visibility water, which has previously been shown for other piscivorous fish (Vøllestad et al., 1986; Andersen et al., 2008; Meager and Batty, 2011).

In general, the present study found that a higher prey density increased consumption rates, potentially mediated by increased prey encounters. However, this is not straightforward due to density-dependent prey behaviour (Travis and Palmer, 2005). For schooling prey, such as roach, encounters do not increase proportionally with increasing prey density. Rather, school size increases, and predator success has been linked to school encounters more than individual encounters (Turesson and Brönmark, 2004). However, group foragers like perch may be able to break up schools and take advantage of larger school sizes at high prey densities (Turesson and Brönmark, 2004), which may explain why perch in the present study were able to exploit the higher prey density. Perch consumption in turbid waters may also be linked to changes in individual prey behaviour. For instance, roach escape distance has shown to be severely reduced in turbid waters (Ranåker et al., 2012). Further, it is well acknowledged that anti-predator behaviours, such as schooling and refuging, weaken at low visibility (Abrahams and Kattenfeld, 1997), which might increase the number of individual encounters.

Moreover, it was somewhat surprising that turbidity level only had a very close to statistically significant effect, despite the high level of turbidities in both moderate (25 NTU) and high turbidity (105 NTU) treatments. Radke and Gaupisch (2005) found limited effects of bentonite turbidity on consumption rates in turbidity levels of 2-8 NTU. Similarly, largemouth bass showed no response to bentonite-induced turbidities up to 37 NTU, but unlike the present study, a clear reduction in consumption rate at $70 \mathrm{NTU}$ (Reid et al., 1999). These findings origi-

Tab. 1. The effect of turbidity and prey density on consumption rate by perch tested with a generalised least square model.

\begin{tabular}{lccc}
\hline & $\mathrm{F}$ & D.f. & $\mathrm{P}$ \\
\hline Intercept & 2.047 & 2 & 0.381 \\
Turbidity & 1.689 & 1 & 0.056 \\
Prey density & 31.418 & 2 & $<0.001^{*}$ \\
\hline
\end{tabular}

D.f., degree of freedom. "Significant results.

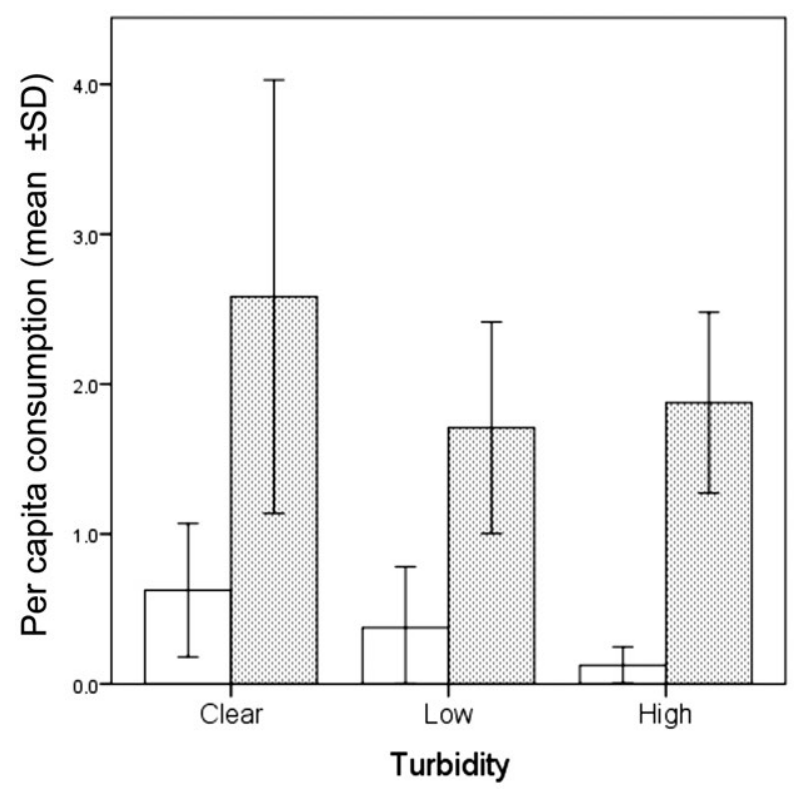

Fig. 1. Mean per capita consumption (number of prey fish) of individual perch at low (white bars) and high (speckled bars) prey density in clear water, moderate and high turbidity water. Whiskers indicate standard deviation (SD). 
nate from experiments with prey densities comparable to the present investigation.

\section{CONCLUSIONS}

The fact that perch is capable of piscivory in high turbidity indicates that reasons other than visibility govern the abundance of large piscivorous perch in high-nutrient lakes. For instance, limitations for younger life stages according to the lower prevalence of underwater vegetation as well as competition with roach may reduce juvenile perch growth and thereby transition to piscivory. Hence, the transition to piscivory for small perch may play a key role in system composition, alternative stable states, and biomanipulation effectiveness in eutrophic lakes.

\section{ACKNOWLEDGMENTS}

The technical support from the staff at National Institute of Aquatic Resources (DTU-Aqua) - Technical University of Denmark and from Lars Båstrup-Spohr is gratefully acknowledged. Financial support was granted by the Danish Angling license funds. Ethical concerns on experimental animal treatment were considered and followed under the ethical laws of Denmark, as well as under permission from the Danish Animal Experiments Inspectorate.

\section{REFERENCES}

Abrahams M, Kattenfeld M, 1997. The role of turbidity as a constraint on predator-prey interactions in aquatic environments. Behav. Ecol. Sociobiol. 40:169-174.

Andersen M, Jacobsen L, Grønkjær P, Skov C, 2008. Turbidity increases behavioural diversity in northern pike, Esox lucius L., during early summer. Fisheries Manag. Ecol. 15:377-384.

Berg S, 1998. Diet of rainbow trout (Onchorhynchus mykiss) stocked as a biomanipulation tool in a eutrophic brackish lake, p. 88-98. In: I.G. Cowx (ed.), Stocking and introduction of fish in freshwater and marine systems. Fishing News Books.

Craig JF, 2000. Percid fishes. Systematics, ecology, and exploitation. Blackwell Science, Oxford: 370 pp.

De Robertis A, Ryer CH, Veloza A, Brodeur RD, 2003. Differential effects of turbidity on prey consumption of piscivorous and planktivorous fish. Can. J. Fish. Aquat. Sci. 60:1517-1526.

Diehl S, 1988. Foraging efficiency of three freshwater fishes: effects of structural complexity and light. Oikos 53:207-214.

Eklöv P, 1992. Group foraging versus solitary foraging efficiency in piscivorous predators: the perch, Perca fluviatilis, and pike, Esox lucius, patterns. Anim. Behav. 44:313-326.

Granquist M, Mattila J, 2004. The effect of turbidity and light intensity on the consumption of mysids by juvenile perch (Perca fluviatilis L.). Hydrobiologia 514:93-101.

Guthrie DM, Muntz WRA, 1993. Role of vision in fish behaviour, pp. 89-121. In T.P. Pitcher (ed.), Behaviour of teleost fishes. Chapman and Hall Publ.

Jeppesen E, Jensen JP, Søndergaard M, Lauridsen T, Landkildehus F, 2000. Trophic structure, species richness and biodiversity in Danish lakes: changes along a phosphorus gradient. Freshwater Biol. 45:201-218.

Jeppesen E, Søndergaard M, Kronvang B, Jensen JP, Svendsen
LM, Lauridsen TL, 1999. Lake catchment management in Denmark. Hydrobiologia 395:419-432.

Meager JJ, Batty RS, 2011. Effects of turbidity on the spontaneous and prey-searching activity of juvenile Atlantic cod (Gadus morhua). Philos. T. Roy. Soc. B 362:2123-2130.

Miner JG, Stein RA, 1996. Detection of predators and habitat choice by small bluegills: effects of turbidity and alternative prey. T. Am. Fish. Soc. 125:97-103.

Nilsson PA, 2001. Predator behaviour and prey density: evaluating density-dependent intraspecific interactions on predator functional responses. J. Anim. Ecol. 70:14-19.

Nurminen L, Pekcam-Hekim Z, Horppila J, 2010. Feeding efficiency of planktivorous perch Perca fluviatilis and roach $R u$ tilus rutilus in varying turbidity: an individual based approach. J. Fish Biol. 76:1848-1855.

Pekcan-Hekim Z, Lappalainen J, 2006. Effects of clay turbidity and density of pikeperch (Sander lucioperca) larvae on predation by perch (Perca fluviatilis). Naturwissenschaften 93:356-359.

Persson L, 1979. Effects of temperature and different food organisms on the rate of gastric evacuation in perch (Perca fluviatilis). Freshwater Biol. 9:99-104

Pinheiro J, Bates D, DebRoy S, Sarkar D, R Development Core Team, 2012. nlme: linear and nonlinear mixed effects models. Available from: http://cran.r-project.org/web/packages/ nlme/index.html

R Development Core Team, 2012. R: a language and environment for statistical computing. R Foundation for Statistical Computing, Vienna, Austria. Available from: http://www.Rproject.org/

Radke RJ, Gaupisch A, 2005. Effects of phytoplankton-induced turbidity on predation success of piscivorous Eurasian perch (Perca fluviatilis): possible implications for fish community structure in lakes. Naturwissenschaften 92:91-94.

Ranåker L, Jönsson M, Nilsson PA, Brönmark C, 2012. Effects of brown and turbid water on piscivore-prey fish interactions along a visibility gradient. Freshwater Biol. 57:1761-1768.

Reid MR, Fox MG, Whillans, TH, 1999. Influence of turbidity on piscivory in largemouth bass (Micropterus salmoides). Can. J. Fish. Aquat. Sci. 56:1362-1369.

Skov C, Nilsson PA, Jacobsen L, Brönmark C, 2007. Habitatchoice interactions between pike predators and perch prey depend on water transparency. J. Fish Biol. 70:298-302.

Travis JMJ, Palmer SCF, 2005. Spatial processes can determine the relationship between prey encounter rate and prey density. Biol. Letters 1:136-138.

Turesson H, Brönmark C, 2004. Foraging behaviour and capture success in perch, pikeperch and pike and the effects of prey density. J. Fish Biol. 65:363-375.

Turesson H, Brönmark C, 2007. Predator-prey encounter rates in freshwater piscivores: effects of prey density and water transparency. Oecologia 153:281-290.

Vøllestad LA, Skurdal J, Qvenild T, 1986. Habitat use, growth, and feeding of pike (Esox lucius L.) in four Norwegian lakes. Arch. Hydrobiol. 108:107-117.

Wellington CG, Mayer CM, Bossenbroek JM, Stroh NA, 2010. Effects of turbidity and prey density on the foraging success of age 0 year yellow perch Perca flavenscens. J. Fish Biol. 76:1729-1741.

Zuur AF, Ieno EN, Walker NJ, Saveliev AA, Smith GM, 2009. Mixed effects models and extensions in ecology with R. Springer, New York: 574 pp. 